\title{
Measuring working memory load effects on electrophysiological markers of attention orienting during a simulated drive
}

Citation for published version (APA):

Ross, V., Vossen, A. Y., Smulders, F. T. Y., Ruiter, R. A. C., Brijs, T., Brijs, K., Wets, G., \& Jongen, E. M. M. (2018). Measuring working memory load effects on electrophysiological markers of attention orienting during a simulated drive. Ergonomics, 61(3), 429-443. https://doi.org/10.1080/00140139.2017.1353708

Document status and date:

Published: 01/03/2018

DOI:

10.1080/00140139.2017.1353708

Document Version:

Publisher's PDF, also known as Version of record

Document license:

Taverne

Please check the document version of this publication:

- A submitted manuscript is the version of the article upon submission and before peer-review. There can be important differences between the submitted version and the official published version of record.

People interested in the research are advised to contact the author for the final version of the publication, or visit the DOI to the publisher's website.

- The final author version and the galley proof are versions of the publication after peer review.

- The final published version features the final layout of the paper including the volume, issue and page numbers.

Link to publication

\footnotetext{
General rights rights.

- You may freely distribute the URL identifying the publication in the public portal. please follow below link for the End User Agreement:

www.umlib.nl/taverne-license

Take down policy

If you believe that this document breaches copyright please contact us at:

repository@maastrichtuniversity.nl

providing details and we will investigate your claim.
}

Copyright and moral rights for the publications made accessible in the public portal are retained by the authors and/or other copyright owners and it is a condition of accessing publications that users recognise and abide by the legal requirements associated with these

- Users may download and print one copy of any publication from the public portal for the purpose of private study or research.

- You may not further distribute the material or use it for any profit-making activity or commercial gain

If the publication is distributed under the terms of Article $25 \mathrm{fa}$ of the Dutch Copyright Act, indicated by the "Taverne" license above, 


\title{
Ergonomics
}

\section{Measuring working memory load effects on electrophysiological markers of attention orienting during a simulated drive}

\author{
Veerle Ross, Alexandra Y. Vossen, Fren T. Y. Smulders, Robert A. C. Ruiter, \\ Tom Brijs, Kris Brijs, Geert Wets \& Ellen M. M. Jongen
}

To cite this article: Veerle Ross, Alexandra Y. Vossen, Fren T. Y. Smulders, Robert A. C. Ruiter, Tom Brijs, Kris Brijs, Geert Wets \& Ellen M. M. Jongen (2018) Measuring working memory load effects on electrophysiological markers of attention orienting during a simulated drive, Ergonomics, 61:3, 429-443, DOI: 10.1080/00140139.2017.1353708

To link to this article: https://doi.org/10.1080/00140139.2017.1353708

\section{曲 Published online: 31 Jul 2017.}

Submit your article to this journal 2

\section{Џll Article views: 435}

Q View related articles $\sqsubset$

View Crossmark data $[\pi$

Citing articles: 4 View citing articles $\Longleftarrow$ 


\title{
Measuring working memory load effects on electrophysiological markers of attention orienting during a simulated drive
}

\author{
Veerle Ross ${ }^{\mathrm{a}}$, Alexandra Y. Vossen ${ }^{\mathrm{b}}$, Fren T. Y. Smulders ${ }^{c}$, Robert A. C. Ruiter ${ }^{d}$, Tom Brijs ${ }^{\mathrm{a}}$, Kris Brijs ${ }^{\mathrm{a}}$, Geert Wets ${ }^{\mathrm{a}}$ \\ and Ellen M. M. Jongen ${ }^{\mathrm{e}}$

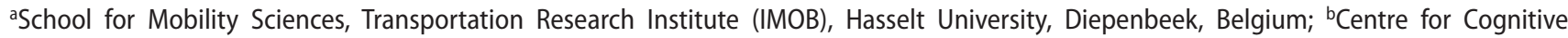 \\ Neuroimaging, University of Glasgow, Glasgow, UK; 'Faculty of Psychology and Neuroscience, Department of Cognitive Neuroscience, Maastricht \\ University, The Netherlands; 'Faculty of Psychology and Neuroscience, Department of Work and Social Psychology, Maastricht University, \\ Maastricht, The Netherlands; ' $F$ Faculty of Psychology and Educational Sciences, Open University, Heerlen, The Netherlands
}

ABSTRACT

Intersection accidents result in a significant proportion of road fatalities, and attention allocation likely plays a role. Attention allocation may depend on (limited) working memory (WM) capacity. Driving is often combined with tasks increasing WM load, consequently impairing attention orienting. This study $(n=22)$ investigated WM load effects on event-related potentials (ERPs) related to attention orienting. A simulated driving environment allowed continuous lane-keeping measurement. Participants were asked to orient attention covertly towards the side indicated by an arrow, and to respond only to moving cars appearing on the attended side by pressing a button. WM load was manipulated using a concurrent memory task. ERPs showed typical attentional modulation (cue: contralateral negativity, LDAP; car: N1, P1, SN and P3) under low and high load conditions. With increased WM load, lane-keeping performance improved, while dual task performance degraded (memory task: increased error rate; orienting task: increased false alarms, smaller P3).

Practitioner Summary: Intersection driver-support systems aim to improve traffic safety and flow. However, in-vehicle systems induce WM load, increasing the tendency to yield. Traffic flow reduces if drivers stop at inappropriate times, reducing the effectiveness of systems. Consequently, driversupport systems could include WM load measurement during driving in the development phase.
ARTICLE HISTORY

Received 14 March 2016 Accepted 5 July 2017

\section{KEYWORDS}

Attention orienting; working memory load; event-related potentials; driving simulation

\section{Introduction}

Driving is a highly complicated task requiring the integration of various attentional, cognitive, sensory and psychomotor functions (Ross et al. 2015; Young and Regan 2007) in road environments of different complexities (Horberry et al. 2006). Even though most countries successfully decreased the number of road fatalities, this number still remains too high with the WHO reporting fatality rates of 1.24 million per year (World Health Organization 2013). Intersection accidents constitute a major problem and encompass a significant proportion of fatalities each year. Often, these accidents result from situations where drivers fail to yield (Bao and Boyle 2009; Sandin 2009; Werneke and Vollrath 2012). Insufficient visuospatial attention allocation has been proposed as an underlying cause for the failure to yield to other road users (Werneke and Vollrath 2012). Real-life tasks such as yielding situations are complex and involve selective attention orienting to relevant information in a complex sensory environment, together with motor control, memory encoding and retrieval. Working memory (WM) provides cognitive resources for the coordination of attentional control. However, available WM capacity is limited (Vossen et al. 2016). Furthermore, the relation between attention and WM may depend on the specific types of both load and attention. Lavie's load theory (Lavie et al. 2004) indicates that WM load disrupts top-down, voluntary attention. However, the same does not hold for bottom-up, reflexive attention (eg Law, Langton, and Logie 2010). At the same time, while reflexive attention is affected by perceptual load, voluntary attention is not (eg Santangelo et al. 2008).

Driving is often combined with secondary tasks that increase WM load, leaving less spare WM capacity to devote to the driving task (Lavie 2010; Recarte and Nunes 2003; Ross et al. 2014). As yielding situations involve top-down orienting of attention, driving behaviour at intersections is expected to be influenced by WM load. Indeed, previous reports indicated that WM load degrades driving performance at intersections as shown by increased crash risks 
and yielding violations (Fu et al. 2013; McEvoy, Stevenson, and Woodward 2007; Neyens and Boyle 2007). WM load not only affects responses to changing environments or sudden events, but also continuous driving measures such as steering and speed management (Allen et al. 2005; Engström, Johansson, and Östlund 2005; Ross et al. 2014). A study from Engström, Johansson, and Östlund (2005) tested the effect of both perceptual load and WM load and found them to impact differentially on continuous driving. The former led to reduced speed and increased lane-keeping variation. Conversely, the latter did not affect speed and resulted in reduced lane-keeping variation. Furthermore, WM load led to increased gaze concentration towards the road centre, which might have been related to the reduced lane-keeping variability.

Measures that can distinguish between various information processing stages are necessary to identify the underlying mechanisms of the influence of WM load (Fort et al. 2013). In contrast to reaction time measures (Kessels, Ruiter, and Jansma 2010), which reflect a convergence of effects in a single outcome measure, electroencephalography (EEG) can provide additional online information of ongoing attentional processes. WM load due to a secondary task has been shown to reduce event-related potential (ERP) amplitude, for the primary and/or secondary task (Prinzel et al. 2003; Strayer, Drews, and Johnston 2003; Ullsperger, Freude, and Erdmann 2000; Wester et al. 2008). Fort et al. (2013) used ERP measurement during a driving-like detection task. To investigate underlying mechanisms affected by WM load, they combined behavioural and ERP measures to investigate the impact of warning systems on visual target processing. Participants had to perform a visual detection task, either alone, or combined with a concurrent problem-solving task. An increase in WM load was associated with an amplitude reduction of $\mathrm{N} 1$ and N2/P3 components, indicating degraded visual information processing in early perceptual stages. In addition, greater WM load delayed reactions to visual targets.

Spatial cueing tasks in which a cue predicts the likely position of a target stimulus are often used to assess attention orienting. The typical finding is that reaction times are faster and responses are more accurate to stimuli that appear at the cued location (valid trials) than to stimuli that appear at an uncued location (invalid trials) (eg Jongen, Smulders, and van der Heiden 2007; Posner 1978). Previous EEG research has identified ERP signatures related to attention orienting in cueing tasks. A sequence of lateralised components with a greater positive or negative voltage over the hemisphere contralateral to the direction of the cue has been related to different stages in the control of attention. These include: the early directing attention negativity (EDAN) occurring at posterior sites (200-400 ms after cue onset), the anterior directing attention negativity (ADAN) at frontocentral sites (300$500 \mathrm{~ms}$ after cue onset) and the late directing attention positivity (LDAP) at posterior sites (500-700 ms after cue onset) (Jongen, Smulders, and van der Heiden 2007; Jongen, Smulders, and Van Breukelen 2006; Murray, Nobre, and Stokes 2011). The EDAN may represent processing of physical properties from the cue that are relevant for attention orienting. Meanwhile, the ADAN and LDAP are related to attention orienting, but do not rely on physical cue properties (Jongen, Smulders, and van der Heiden 2007; Van Velzen and Eimer 2003). The former relates to frontal cortex top-down control as well as maintenance of spatial redirection of attention, the latter relates to the anticipatory biasing of brain regions involved in location coding and target processing (McDonald and Green 2008; Vossen et al. 2016). Subsequently, a sequence of ERP components is evoked in response to the target stimulus over lateral occipital sites consisting of an early P1 component (onset at about $100 \mathrm{~ms}$ ), followed by an $\mathrm{N} 1$ component (onset at about $150 \mathrm{~ms}$ ). Modulatory effects of attention on processing of the target stimulus are reflected by $\mathrm{P} 1$ and $\mathrm{N} 1$ amplitude enhancements for attended stimuli in comparison to unattended stimuli (Herrmann and Knight 2001; Luck et al. 1990; Ruiter et al. 2006). Finally, ERP components related to non-spatial attention indicate attentional selection and cognitive processing of stimulus features (eg movement). Selection negativity ( $\mathrm{SN}$ ) is a broad negativity (150-300 ms after stimulus onset) whose location varies with the nature of the to-be-attended feature. $\mathrm{P} 3$ is a late positivity ( $300 \mathrm{~ms}$ after stimulus onset) generated by multiple distributed generators, indicating distribution of cognitive resources and thought to reflect an update of stimulus processing with WM information. Furthermore, P3 reflects post-perceptual processes necessary to carry out the task (Herrmann and Knight 2001; McGinnis and Keil 2011; Nobre, Sebestyen, and Miniussi 2000; Pitts et al. 2014; Ruiter et al. 2006; Shedden and Nordgaard 2001).

Cueing tasks typically involve simplified task situations and abstract shapes, while tasks in real life are more complex and require the allocation of cognitive resources to multiple subtasks to achieve behavioural goals (Vossen et al. 2016). Lee, Lee, and Boyle (2009) adapted a cueing task to a complex virtual driving situation where pedestrian crossing-signs predicted pedestrians'spatial location. WM load was introduced by a verbal-auditory task resembling driver interaction with in-vehicle technology (ie requiring participants to listen and respond to auditory messages). It was found that WM load increased the reaction time to detect pedestrians. However, the study did not include online EEG measurements of attentional processes. Vossen et al. (2016) used a computerised orienting task visually resembling an intersection environment to investigate WM load effects on attention orienting. Participants had 
to covertly (ie without moving the eyes) allocate attention to cars appearing on the left or right side of an intersection. They were instructed to press a button as quickly as possible whenever a vehicle appearing at the attended location started to move towards the intersection, while stationary cars and moving cars at the unattended location could be ignored. The behavioural response therefore is comparable to yielding. Compared to a typical cueing task, where participants are asked to respond to both cued and uncued target stimuli, the instruction to only respond to a subset of the possible targets (ie selection) requires more attention. This was supported by the results from Jongen, Smulders, and van der Heiden (2007), who found that the ADAN and LDAP were absent in cases of lower attentional selection (ie mere detection). Therefore, to investigate effects of WM load on EEG markers of attention orienting, we also gave the instruction in our study to respond only to a subset of the cars (ie targets were defined as cars appearing at the attended location that started to move towards the intersection). Furthermore, fewer motor response trials allowed us to investigate more car and target ERPs in a limited time. In Vossen et al. (2016) an auditory-verbal version of the memory task employed by de Fockert et al. (2001) was used to additionally introduce WM load, requiring participants to remember and respond to a set of digits in an ascending (ie low WM load, 01234) or a randomised order (ie high WM load, eg 03421). ERP results indicated that drivers used the arrow signs to direct their attention. When WM load was high, performance in the memory task and the concurrent orienting task decreased. Furthermore, ERP components indicated a delay of attention orienting for high vs. low WM load. However, although this study attempted to create a driving-like context, continuous measures of driving performance cannot be included in a static lab environment. These results therefore needed to be replicated under ecologically more valid conditions.

The current study ( $n=22)$ aimed to replicate and extend the study by Vossen et al. (2016) by investigating WM load effects on electrophysiological markers of attention orienting. We aimed to replicate WM load effects on brain and behavioural responses during a concurrent driving task in a driving simulator. The latter enabled us to investigate in addition how WM load affects lane-keeping, a continuous measure of driving performance. Therefore, this study translated the orienting task from Vossen et al. (2016) to a simulated driving environment, increasing ecological validity.

\section{Method}

\section{Participants}

Twenty-two participants with a preliminary or permanent driver's licence (ie at least $20 \mathrm{~h}$ of driving experience) were included in this study (12 women; age: range $=17-33$, mean $=22.91, \mathrm{SD}=4.23$; experience in kilometres: range $=210,000-360,365$, mean $=56,891, S D=92,237$ ). For two participants, part of the EEG data was compromised due to technical difficulties; however, the behavioural data were complete and therefore included in the analyses. All participants gave informed consent and received a gift voucher as well as two cinema tickets with a total value of $€ 34$ upon completion of the experiment.

\section{Driving simulator}

The experiment was conducted with a fixed-based STISIM M400 (Systems Technology Incorporated) driving simulator including a force feedback steering wheel, brake pedal, accelerator, clutch and automatic transmission. The virtual environment was displayed on a $180^{\circ}$ field screen by a three-part projection system (Figure 1). Three projectors offered a resolution of $1024 \times 768$ pixels, each, and a $60-\mathrm{Hz}$ frame rate. Typical sounds from an engine were added to the simulation. Data were collected at frame rate.

\section{EEG recording}

A BioSemi ActiveTwo System (BioSemi, Amsterdam/NL), with sintered $\mathrm{Ag} / \mathrm{AgCl}$ electrodes, and an ActiveTwo head cap were used to record reference-free EEG with a sampling

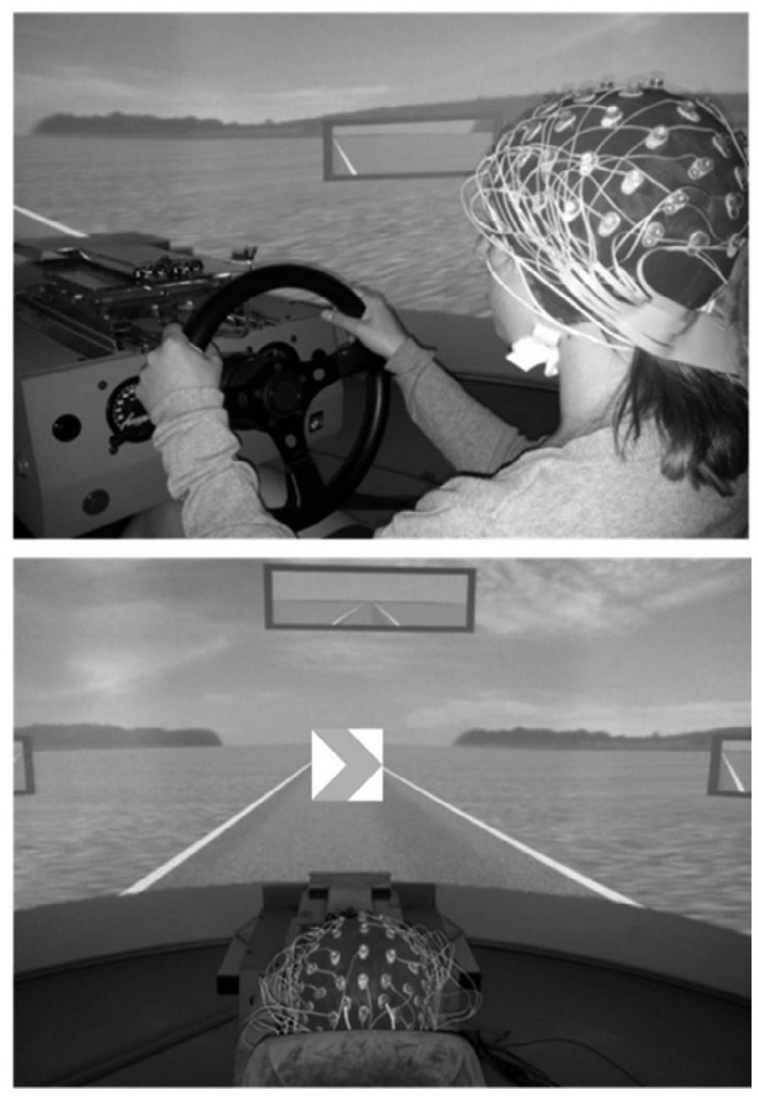

Figure 1. Experimental environment. 
rate of $256 \mathrm{~Hz}$. Scalp activity was measured at 64 electrode locations following the international 10-20 system (Figure 1). Following the BioSemi, protocol electrode offsets were kept below $40 \mathrm{mV}$ (note that BioSemi does not provide impedance measures). The EEG signal was re-referenced offline to the average mastoid signal. Activity related to horizontal and vertical eye movements was recorded from four electrodes (ie two at the outer canthi, one above and one below the left eye).

\section{Tasks}

\section{Memory task}

The memory task was identical to the one in Vossen et al. (2016; see also: de Fockert et al. 2001). Participants were presented with verbally recorded digit sets from one to four, recorded at a rate of $43 \mathrm{bpm}$. In the low WM load condition, the order of the digits was fixed (ie 01234). In the high WM load condition, the order of the digits was random (eg 03421). Each set lasted about 5-6 s. When an auditory probe consisting of a single digit (eg 3 ) was presented, participants had to respond by saying out loud the number that followed this probe in the set they had previously heard (eg 4). To be able to use all four digits, sets always started with zero. Therefore, zero could act as a probe but was never the correct response. The next set of digits was presented after a $2 \mathrm{~s}$ interval. There were $72 \mathrm{WM}$ load trials per condition (ie low and high WM load). Verbal responses were manually recorded by the experimenter.

\section{Orienting task}

The orienting task was designed to match Vossen et al. (2016) as closely as possible while keeping simulator software limitations into account (ie feedback during the experimental trial or reduced luminance of the stimuli were not possible). The simulated driving environment consisted of a one-lane road on which participants responded to yielding situations at 512 unsignalised priority intersections, the most used roadway junction in highway transportation systems ( $\mathrm{Wu} 2001$ ). The timing (see also Figure 2) was adapted from a study investigating similar ERP components of attention orienting (Jongen, Smulders, and Van Breukelen 2006). At each intersection, a cue in the shape of a red arrow in a white square (ie resembling an actual road sign, see also Figure 1), was presented for 400 ms. After a cue target interval of $1217 \mathrm{~ms}$, a car appeared on the left-or-right side of the road, centred at a visual angle of about $7^{\circ}$ from the centre of the screen. After a stationary interval of $260 \mathrm{~ms}$, the car either started to move for 34 ms towards the intersection, or remained stationary for $34 \mathrm{~ms}$. After that, stationary and moving cars disappeared. Participants were instructed to covertly orient attention

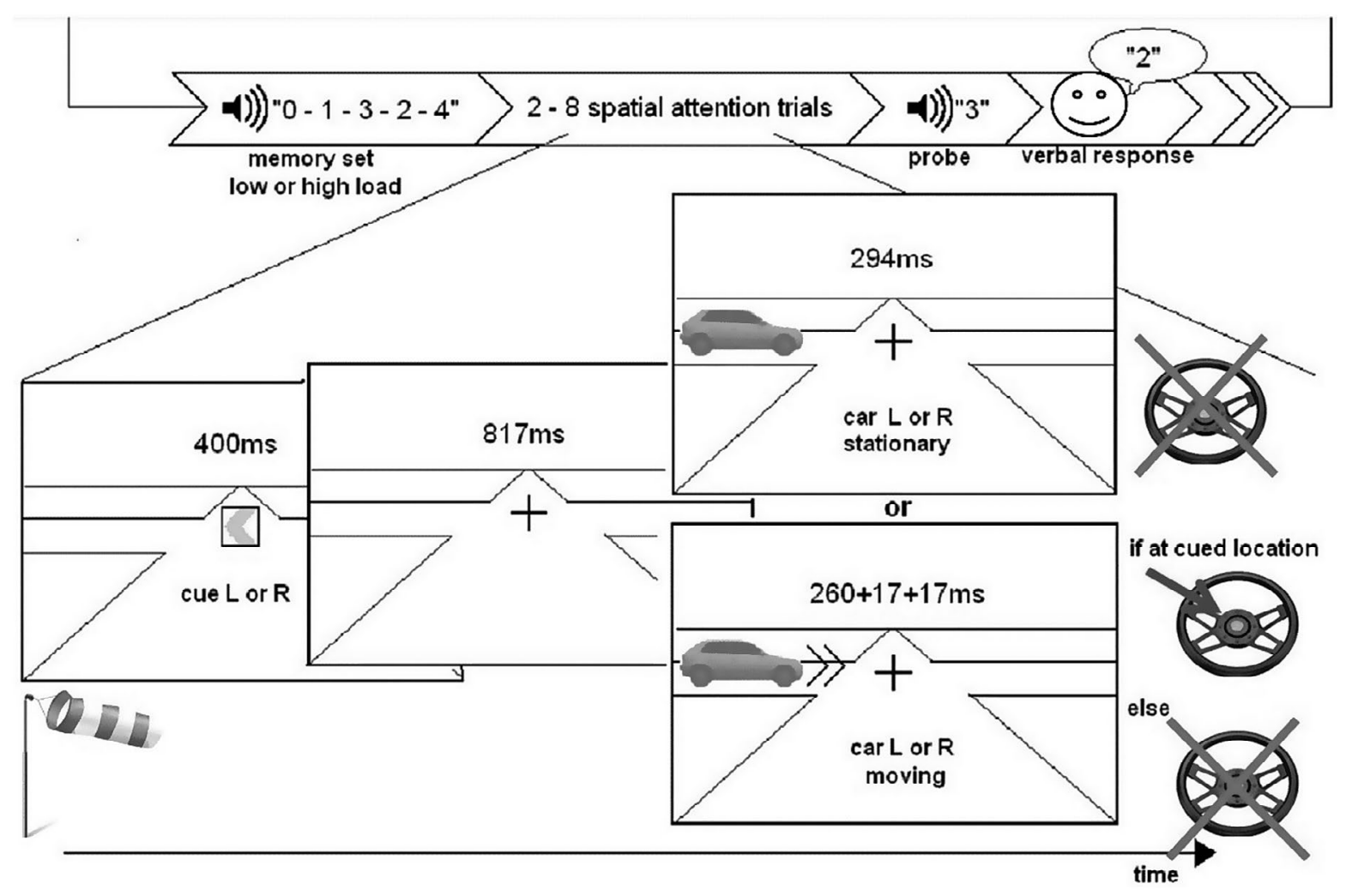

Figure 2. Schematic representation of the dual task. Source: (Vossen et al. 2016). 
towards the side indicated by the arrow, and only respond to moving car stimuli appearing at the location previously indicated by the cue. Although the cues indicated the following task-relevant location, they were non-predictive as to whether an actual target car would appear. Cruise control was used to drive at a constant speed (ie $70 \mathrm{~km} / \mathrm{h}$ ) to control task timing and minimise EEG artefacts due to movement. A button-press was used to substitute for a brake response without reducing speed, to avoid the additional influence of changing speed. Although the horn button was used, no actual horn was sounded. Accuracy and response time of the brake responses served as the behavioural outcome measures of the orienting task.

\section{Dual task}

Figure 2 shows a schematic representation of the dual task consisting of the concurrent execution of the memory and orienting tasks. The memory task served to manipulate WM load in the orienting task. Similar to Vossen et al. (2016), each WM load condition (low vs. high) consisted of 72 memory trials and 256 orienting trials, with 32 orienting trials in each of the eight stimulus conditions: Cue Direction (left vs. right) X Car Location (left vs. right) X Motion (stationary vs. moving). Orienting trial order was randomized within each WM load condition. The instructions were to respond as quickly and accurately as possible to both tasks. After every memory set, participants performed a variable amount of orienting trials (ie 2-8), after which they needed to respond to the probe. Orienting trials were presented in sequences of two to eight trials in order to keep the probe unexpected so that constant memory rehearsal was encouraged (within each load condition: 25 sequences of 2 orienting trials, 17 of 3,12 of 4,8 of 5,5 of 6,3 of 7 , and 2 of 8 trials). The order of low and high load dual task trials was also randomised.

\section{HEOG calibration task}

The Horizontal electro-oculogram (HEOG) calibration task was adapted from Jongen, Smulders, and van der Heiden (2007). Participants had to follow a white dot on a grey background that moved from a central location to the leftor-right side of the screen (ie equivalent to the car location in the orienting task), as well as $3^{\circ}$ up and down (10 trials per condition). The dot returned to the starting position after $1.5 \mathrm{~s}$ (Vossen et al. 2016). This task provided a calibration for horizontal eye movements, linking the voltage measurements to lateral movement. Trials with horizontal eye movements could thus be discarded to assure that only trials with covert attention allocation were included.

\section{Continuous driving task}

Continuous driving control can be measured by providing a controlled stimulus to the driver or the vehicle and measuring the driver response to those manipulations. Examples of controlled stimuli are wind gusts and roadway curvature (Allen et al. 2005). Therefore, to make the task of lane-keeping more difficult on the virtual straight road, wind gusts were added to measure lane-keeping performance (van Kessel et al. 2013). Wind in the form of a variable lateral force (ie wave pattern computed by the sum of three sine waves). Lateral displacement over time was implemented as a wave pattern consisting of the sum of three sinusoids with 3,9 and 18 cycles per minute. Participants were instructed to try to remain in the middle of the driving lane, requiring active lane-keeping.

\section{Procedure}

Participants were given a cover story that this study investigated cruise control effects on reaction time. The orienting and memory tasks were practiced separately (40 trials and 60 trials, respectively) and combined (76 dual task trials). Verbal feedback was provided by the experimenter during training, and sessions were repeated if the performance level dropped below $80 \%$. No feedback was provided during the experimental trials. The actual experiment consisted of three experimental blocks separated by selftimed breaks and two short regular drives (each $5.5 \mathrm{~km}$ in a simulated rural and urban driving environment) to reduce fatigue effects. The experimental task consisted of 72 memory trials and 256 orienting trials.

\section{Preprocessing}

EEG data were processed using EEGlab and MATLAB (MathWorks, Natick/US).

\section{Dual task}

EEG data were filtered between 0.1 and $35 \mathrm{~Hz}$. Epochs of $4 \mathrm{~s}$ (ie an orienting trial) were extracted from $200 \mathrm{~ms}$ before cue onset until $1 \mathrm{~s}$ after car offset. Epochs were demeaned by subtracting the average amplitude across the whole epoch. Noisy epochs were removed by visual inspection (mean \% rejected epochs $=0.40, \mathrm{SD}=0.47$ ). Blink and artefact identification/removal were based on independent component analyses (ICA) (mean number of rejected components $=9.18, \mathrm{SD}=2.13$ ). Remaining noisy epochs (mean $\%$ rejected epochs $=1.30, S D=2.36$ ) were removed after a second visual inspection. The remaining epochs were baseline ( $200 \mathrm{~ms}$ before stimulus onset) corrected before entering the ERP analyses.

\section{HEOG calibration task}

EEG data were filtered between 0.1 and $10 \mathrm{~Hz}$. Epochs of $1 \mathrm{~s}$ were time-locked to dot movement and baseline corrected (200 ms before). The median amplitude was first 
calculated per epoch, and then across trials, for left-andright eye movements separately. Thirty-five per-cent of the average of left and right medians served as the criterion for detecting horizontal eye movements. Trials of the main experiment were rejected if the bipolar HEOG derivation exceeded this criterion (mean \% rejected epochs $=20.18$, $S D=23.07)$. Two participants were excluded after HEOG correction (ie 74 and $75 \%$ of the trials were rejected). On average, 90.15 trials were rejected (range 1-350) and 399.6 trials remained from the 512 trials.

\section{Measurements}

Statistical analyses were performed with IBM SPSS statistics 20 software with a significance level of $\alpha=0.05$.

\section{Memory task}

The error rate in the memory task was calculated for the complete sample $(n=22)$ as the percentage of incorrect verbal responses separately for the low and high WM load condition.

\section{Orienting task}

Hits and false alarms rates determined sensitivity $d^{\prime}$ (ie the distance between signal and noise) and response bias $c$ (ie favouring a response regardless of the stimulus). Reaction times to targets, $d^{\prime}$ and $c$, and hit and false alarm rates of the complete sample $(n=22)$ were entered in three repeated measures analyses of variance (RMANOVA) with factor WM load (low/high).

\section{Event-related potentials}

ERPs were obtained by averaging time-locked activity in response to cue onset (ADAN, EDAN, LDAP) or car onset $(P 1, N 1, S N, P 3)$. Only trials with a correct response were included. Five participants with too few trials per condition (ie cue $<50$, car $<20$ ) were excluded from the analyses. Note that these participants were still included in the analysis of the remaining analyses to retain greater statistical power.

Cue ERPs. Epochs related to cue onset were sorted by cue direction and WM load, and averaged ( $n=17$, mean number of trials $=96.68$, SD trials $=19.50$ trials). Average ERPs recorded over the right hemisphere (eg F8) when attention was oriented to the left were pooled with those of the left hemisphere (eg F7) when attention was oriented to the right, to reflect processing in the hemisphere contralateral to the direction of attention. Likewise, ERPs recorded over the hemisphere ipsilateral to the direction of attention were pooled. Thus, we refer to electrode pair $\mathrm{F} 7 / 8$ qualified by the hemisphere with respect to the cued location. To investigate the presence of ADAN, we chose the anterior electrode pairs F7/8 and FC5/6. To investigate the presence of EDAN and LDAP, the posterior electrode pairs $\mathrm{P} 7 / 8$ and $\mathrm{PO} 7 / 8$ were selected. Time windows for the analyses were selected based on previous literature (we refer to the introduction for the literature overview) and visual inspection of the cue ERPs. See Figures 3 and 4 for grand average cue ERPs to the cued direction, and hemispheric differences in Cue ERPs, respectively. The visual inspection in the time window of interest (ie 300-500 ms) for the ADAN showed that this component was not replicated with the current task conditions (ie top two panels Figure 4). Three potential components were identified in the lower two panels of Figure 4. Mean amplitude in these time windows (50-100, 150-200, and 500-650 ms) in these electrode pairs were entered into a RMANOVA with factors hemisphere (ipsi-/contralateral), WM load (low/high), and electrode (respective sets of anterior vs. posterior electrode pairs).

Car ERPs. Trials related to car onset were sorted by cue direction, car location, motion condition (stationary or moving), and WM load, and averaged ( $n=14$, mean number of trials $=28.70, S D=2.16$ trials per condition and participant). Based on the combination of cue direction and car location, trials were pooled depending on whether cars appeared on the attended or unattended side. ERPs at corresponding electrode pairs over the left and right hemisphere were averaged to avoid confounding of target processing with cue-related lateralisation (Jongen, Smulders, and van der Heiden 2007). Here, we refer to the average across sites (eg P7, P8) as electrode pair (P7/8). The following electrodes and electrode pairs were investigated: $\mathrm{Fz}, \mathrm{Cz}, \mathrm{Pz}, \mathrm{Oz}, \mathrm{P} 7 / 8, \mathrm{PO} 7 / 8$ (see Figure 5). P1 and $\mathrm{N} 1$ were investigated on the averaged $\mathrm{P} 7 / 8$ and $\mathrm{PO} 7 / 8$, $\mathrm{SN}$ on $\mathrm{Fz}$ and $\mathrm{Cz}$, and $\mathrm{P} 3$ on $\mathrm{Fz}, \mathrm{Cz}, \mathrm{Pz}$, and $\mathrm{Oz}$. Time windows were again selected based on previous literature and visual inspection of the car ERPs (see Figure 5). Mean amplitudes in the following time windows (120-150, 170-200, $300-400$, and $520-650 \mathrm{~ms}$ ) were entered into a RMANOVA. For P1 and N1, we conducted a RMANOVA with factors attention (attended vs. unattended, depending on cued location), WM load (low vs. high) and electrode (as specified above). For SN and P3, (after motion onset), motion (stationary vs. moving) was included as additional factor in the RMANOVA.

\section{Continuous driving task}

Lane-keeping was assessed by calculating the standard deviation of the lateral lane position (SDLP). SDLP is a measure of road tracking precision that represents a reliable characteristic of individual driving performance and is sensitive to driver impairment, for instance due to workload or various drugs (De Waard 1996; Ramaekers 


\section{low WM load}
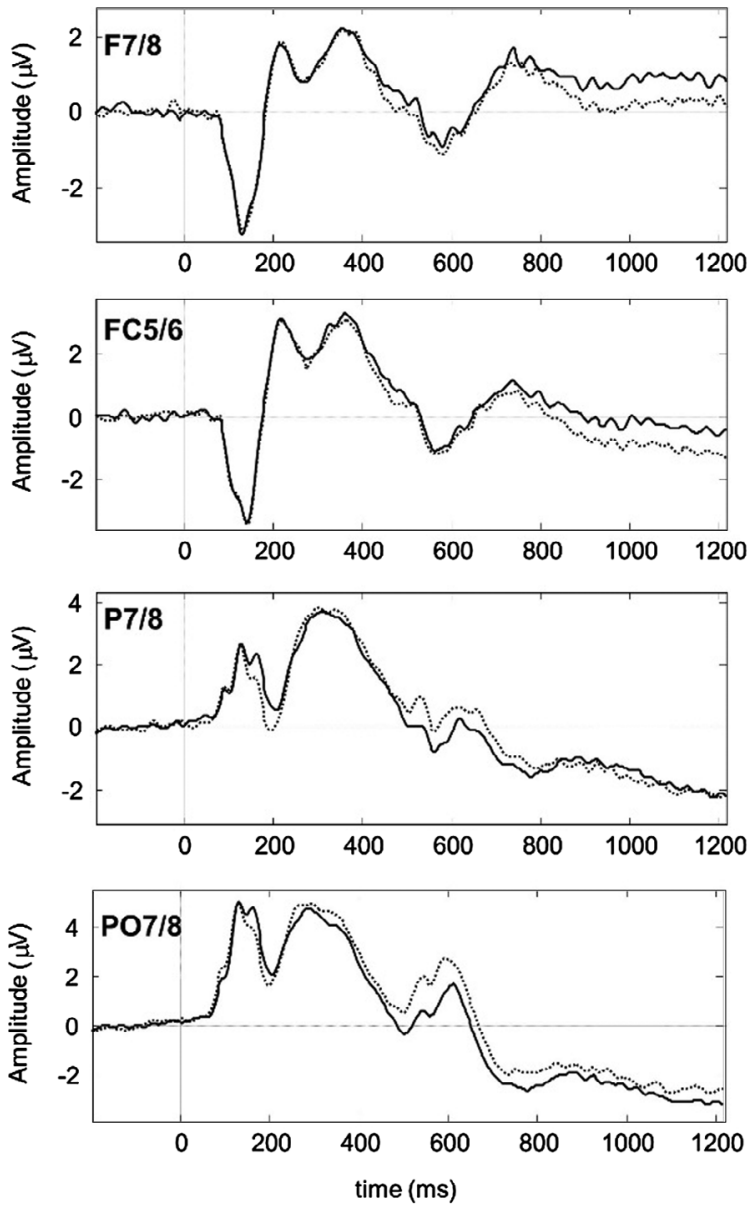

high WM load
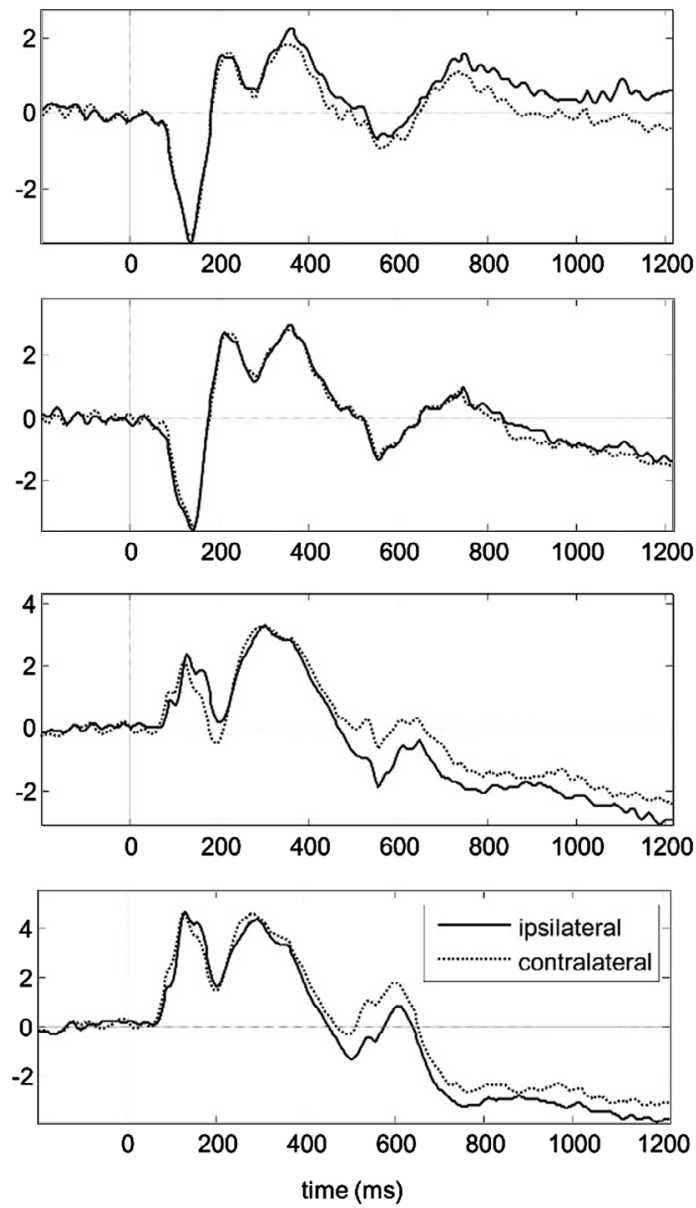

Figure 3. Grand average cue ERPs to the cued direction, under low (left column) and high WM load (right column), recorded ipsilateral (solid line) or contralateral (dotted line) electrodes.

2003; Ross et al. 2015). SDLP was collected throughout the entire scenario for the total sample $(n=22)$. The first $500 \mathrm{~m}$ (ie cruise control initiation) and segments with lane excursions were excluded from the analyses. During the programming of the driving scenario, road segments were marked as occurring under low and high load, respectively. This allowed to compare lane-keeping performance in both WM load conditions. SDLP was entered in a RMANOVA with factor WM load (low/high). To determine whether lane-keeping varied with WM load, we conducted a Pearson correlation analyses (onetailed) between SDLP and the error rate on the memory task.

\section{Results}

\section{Dual task}

\section{Memory task}

Error rates (\% error) in the memory task were significantly higher in the high than in the low WM load condition (low: mean $=2.40, \mathrm{SD}=2.65$; high: mean $=9.41, \mathrm{SD}=7.07$; $\left.\mathrm{F}(1,21)=23.58, p<.001, \eta \rho^{2}=0.53\right)$.

\section{Orienting task}

Reaction times (median, in ms) were unaffected by WM load (low: mean $=454.09, \mathrm{SD}=55.99$; high: mean $=453.18$, $\left.\mathrm{SD}=59.05 ; \mathrm{F}(1,21)=0.04, p=.85, \eta \rho^{2}<=0.01\right)$. There was a trend towards lower sensitivity under high load as indicated by a lower $d^{\prime}$ (low: mean $=3.72, \mathrm{SD}=0.68$; high: mean $=3.50, \mathrm{SD}=0.71 ; F=4.09, p=.06, \eta \rho^{2}=0.16$ ), while WM load did not affect the criterion c (low: mean $=0.28$, $\mathrm{SD}=0.25$; high: mean $=0.21, \mathrm{SD}=0.35 ; F=1.47, p=0.24$, $\left.\eta \rho^{2}=0.07\right)$. With increased WM load, participants thus showed a trend towards a decline in detection performance that was not due to a change in response bias. Separate RMANOVAs were conducted to determine whether WM load increased hits and/or false alarms, allowing interpretation in terms of traffic safety implications. Hits were not significantly affected by WM load (low: mean $=92.12 \%$, $\mathrm{SD}=7.00$; high: mean $=91.05 \%, \mathrm{SD}=8.79 ; \mathrm{F}(1,21)=0.67$, 

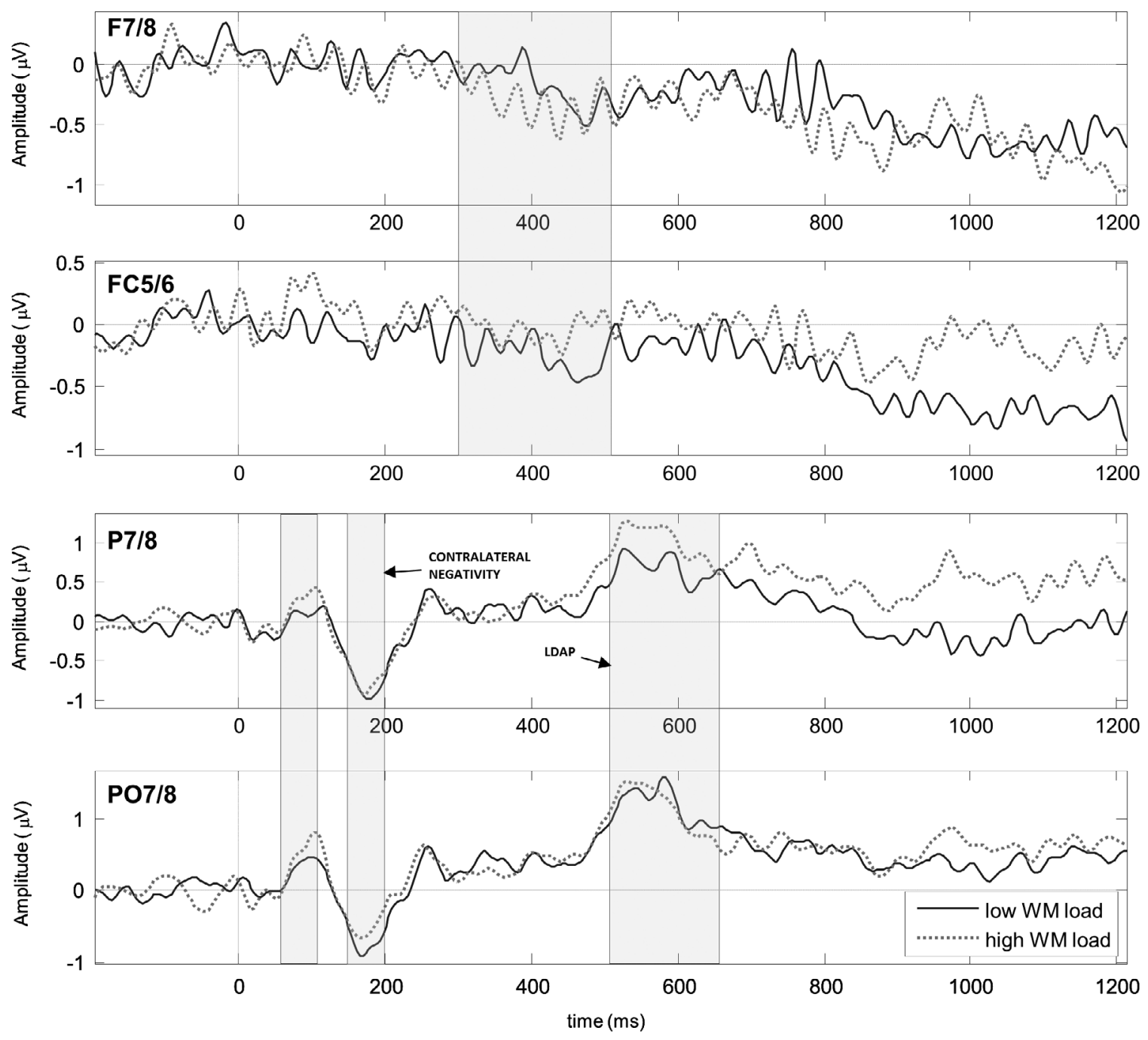

Figure 4. Hemispheric differences in Cue ERPs (contra- minus ipsilateral electrodes).

Notes: Grey shaded areas indicate the time windows of interest. The names of the components are added in black font, except for the window where no ADAN was found (ie only window for F7/8 and FC5/6) and where the early positivity was not confirmed by statistical analyses (ie first window for P7/8 and PO7/8).

$\left.p=.42, \eta \rho^{2}=0.03\right)$. False alarms however were significantly affected by WM load (low: mean $=0.57 \%, \mathrm{SD}=0.71$; high: mean $=1.16 \%$, SD $=1.39 ; \mathrm{F}(1,21)=5.70, p=0.03$, $\eta \rho^{2}=0.214$ ), indicating an increase in false alarms under high WM load.

\section{Event-related potentials}

\section{Cue ERPs}

See Figure 4 for a visualisation of the time windows and the significant ERP components (ie contralateral negativity and LDAP) in response to the cue. The main effect of hemisphere was not significant in the early time window that includes an early positive component indicating sensory processing of the arrow cues $(50-100 \mathrm{~ms}, \mathrm{~F}(1,16)=0.71$, $\left.p=.41, \eta \rho^{2}=0.04\right)$. A significant main effect of hemisphere (ipsi vs. contralateral) confirmed a contralateral negativity $\left(150-200 \mathrm{~ms}, \mathrm{~F}(1,16)=7.49, p=.015, \eta \rho^{2}=0.32\right)$ and a contralateral positivity (LDAP: $500-650 \mathrm{~ms}, \mathrm{~F}(1,16)=$ $40.25, p<0.001, \eta \rho^{2}=0.72$ ), indicating interpretation of cue direction and directing of attention. There was no significant effect of WM load on these components.

\section{Car ERPs}

See Figure 5 for a visualisation of the time windows and the significant ERP components (ie P1, N1, SN, and P3) in response to the car under low and high WM load. Separate RMANOVA's were conducted per component. There were main effects of attention in the windows containing $\mathrm{P} 1$ $\left(120-150 \mathrm{~ms}, \mathrm{~F}(1,13)=9.09, p=.01, \eta \rho^{2}=0.41\right)$ and $\mathrm{N} 1$ $\left(170-200 \mathrm{~ms}, \mathrm{~F}(1,13)=5.97, p=0.03, \eta \rho^{2}=0.32\right)$ at $\mathrm{P} 7 / 8$ and $\mathrm{PO} / \mathrm{8}$, reflecting greater absolute amplitudes of these components for validly vs. invalidly cued car stimuli, indicating that processing of the car was enhanced by attention. No WM load effects were found for P1 or N1. A main effect of attention was found for SN (300-400 ms, 

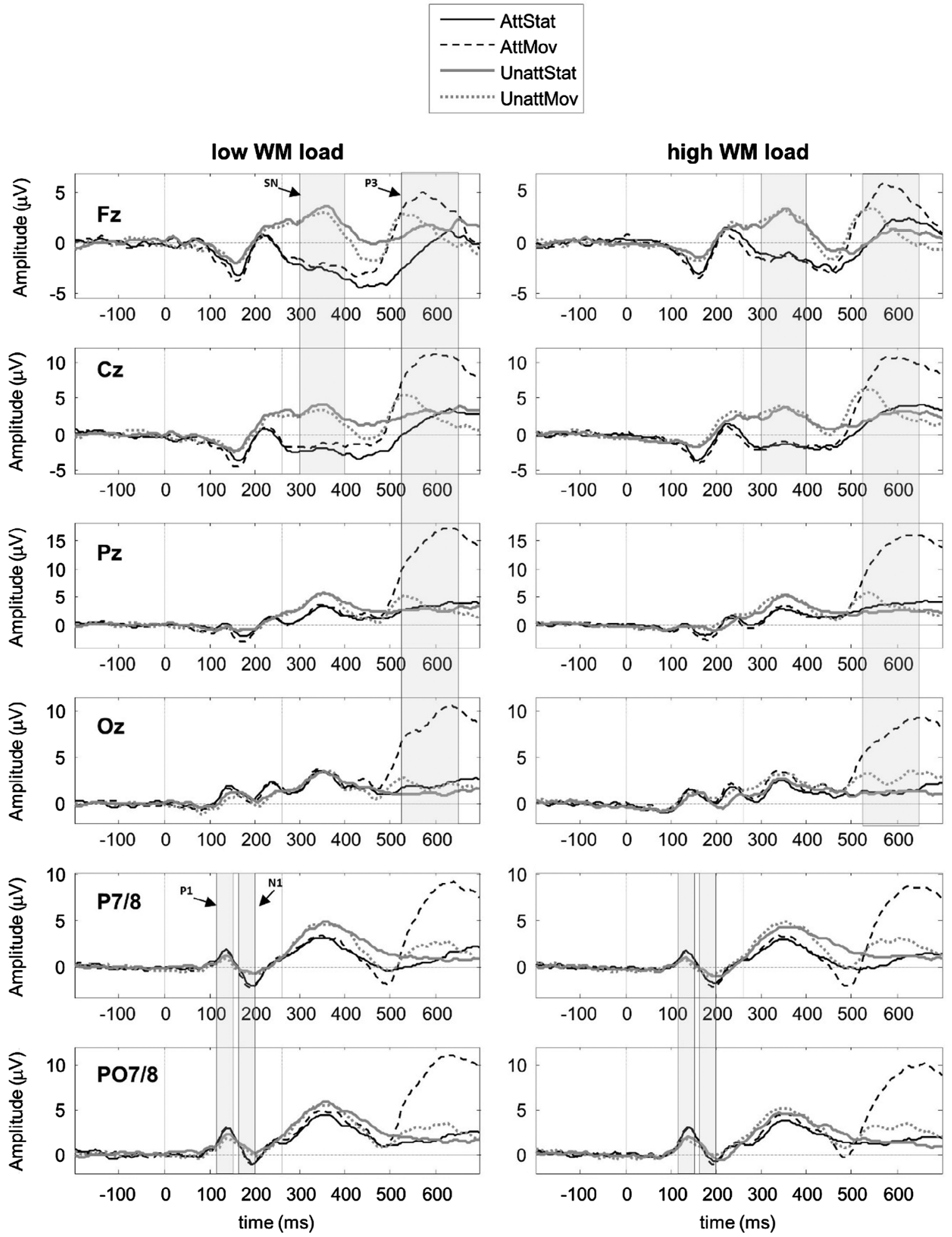

Figure 5. Car ERPs, averaged across ipsi- and contralateral electrodes, under low (left column) and high WM load (right column). Notes: Grey shaded areas indicate the time windows of interest, the name of the components are added in black font.

$\left.\mathrm{F}(1,13)=48.54, p<0.001, \eta \rho^{2}=0.79\right)$ at $\mathrm{Fz}$ and $\mathrm{Cz}$, indicating non-spatial processing of car features. Again, no WM load effects were found. Finally, with respect to the target (ie cued car that is moving), for P3 (520-650 ms) two significant three-way interactions were found (attention by movement by electrode, $\mathrm{F}(1,13)=17.21, p<.001$, $\eta \rho^{2}=0.57$; attention by WM load by electrode, $F(1,13)$ $=5.89, p=0.01, \eta \rho^{2}=0.32$ ). Therefore, for $\mathrm{P} 3$, separate RMANOVA's were conducted per electrode $(\mathrm{Fz}, \mathrm{Cz}, \mathrm{Pz}$, and $\mathrm{Oz}$ ), with factors attention (attended/unattended), 
Table 1. P3 means and standard errors describing Attention by Movement (Att*Mov) and Attention by Load (Att*Load) contrast.

\begin{tabular}{|c|c|c|c|c|c|c|c|c|c|c|c|}
\hline \multicolumn{6}{|c|}{ Att*Mov } & \multicolumn{6}{|c|}{ Att*Load } \\
\hline Electrode & Condition & $M$ & SE & $F$ & $p$ & Electrode & Condition & M & SE & $F$ & $p$ \\
\hline \multirow[t]{4}{*}{$\overline{F z}$} & AS & 0.48 & 1.38 & 10.10 & $0.01^{*}$ & $\mathrm{Fz}$ & $\mathrm{AL}$ & 1.74 & 1.32 & 4.50 & $0.05^{*}$ \\
\hline & AM & 4.32 & 1.31 & & & & $\mathrm{AH}$ & 3.05 & 1.24 & & \\
\hline & US & 1.07 & 0.64 & & & & UL & 1.39 & 0.71 & & \\
\hline & UM & 1.52 & 0.79 & & & & UH & 1.21 & 0.78 & & \\
\hline \multirow[t]{4}{*}{$\mathrm{Cz}$} & AS & 2.55 & 1.43 & 22.13 & $<0.001^{* *}$ & $\mathrm{Cz}$ & $\mathrm{AL}$ & 6.04 & 1.50 & 0.02 & 0.90 \\
\hline & AM & 9.81 & 1.81 & & & & $\mathrm{AH}$ & 6.29 & 1.51 & & \\
\hline & US & 2.87 & 0.88 & & & & UL & 3.16 & 1.36 & & \\
\hline & UM & 3.60 & 1.03 & & & & UH & 3.30 & 1.26 & & \\
\hline \multirow[t]{4}{*}{$\mathrm{Pz}$} & AS & 3.40 & 1.28 & 77.79 & $<0.001^{* *}$ & $\mathrm{Pz}$ & $\mathrm{AL}$ & 9.05 & 1.62 & 0.20 & 0.67 \\
\hline & $A M$ & 14.28 & 2.13 & & & & $\mathrm{AH}$ & 8.63 & 1.70 & & \\
\hline & US & 2.48 & 0.78 & & & & UL & 3.08 & 0.74 & & \\
\hline & UM & 3.71 & 0.81 & & & & UH & 3.11 & 0.90 & & \\
\hline \multirow[t]{4}{*}{$\mathrm{Oz}$} & AS & 1.60 & 0.85 & 63.76 & $<0.001^{* *}$ & $\mathrm{Oz}$ & $\mathrm{AL}$ & 5.42 & 0.97 & 6.16 & $0.03^{*}$ \\
\hline & AM & 8.24 & 1.26 & & & & $\mathrm{AH}$ & 4.41 & 1.00 & & \\
\hline & US & 1.17 & 0.39 & & & & UL & 1.55 & 0.48 & & \\
\hline & UM & 2.45 & 0.43 & & & & $\mathrm{UH}$ & 2.06 & 0.40 & & \\
\hline
\end{tabular}

Notes: $\mathrm{AS}=$ Attended Stationary, AM = Attended Moving, US = Unattended Stationary, UM = Unattended Moving, AL $=$ Attended Low load, AH $=$ Attended High load, $\mathrm{UL}=$ Unattended Low load, $\mathrm{UH}=$ Unattended High load.

${ }^{*} p \leq .05$ (one-tailed); ${ }^{* *} p \leq .01$ (one-tailed).

WM load (low/high), and movement (stationary/moving). Significant interactions between attention and movement (Table 1) were found for all four electrodes indicating that an increase in P3 amplitude for moving as opposed to stationary cars was greater at attended than at unattended locations. A significant interaction between attention and WM load (see Table 1) was found at $\mathrm{Oz}$, indicating that an increase in P3 amplitude for attended as opposed to unattended cars was smaller under high than under low WM load conditions. The same interaction showed a trend towards significance at $\mathrm{Fz}$.

\section{Continuous driving}

Compared to the low WM load condition, SDLP decreased significantly in the high WM load condition indicating higher lane-keeping performance with increased WM load (low: mean $=0.040, S D=0.01$; high: mean $=0.037$, $\left.\mathrm{SD}=0.01 ; F=9.09, p=0.01, \eta \rho^{2}=0.30\right)$. The correlation analyses indicated a trend towards significance $(r=-0.348$, $p<=0.05$ ) between SDLP in the high WM load and the error rate to the memory task in the high WM load condition (Table 2).

\section{Discussion}

Extending on Vossen et al. (2016), this study ( $n=22)$ was the first to investigate the effect of WM load on ERPs related to attention orienting in a simulated driving environment, while including a continuous measure of driving performance (ie lane-keeping). The results showed that typical ERP markers of attention orienting that are usually observed in laboratory tasks were also present in a simulated driving environment. These results support the potential for identifying future research and the development of hypotheses with respect to attention orienting. In accordance with Vossen et al. (2016), we found markers in response to the cue (contralateral negativity and LDAP), attentional modulation of the car (P1, N1 and SN), and target evaluation in response to movement (P3). Similar to Vossen et al. (2016), the effect of movement onset was larger at attended than at unattended locations, indicating an effective filtering mechanism. The early negativity appeared too early (ie 150-200 ms) to be considered an EDAN (Jongen, Smulders, and van der Heiden 2007; Murray, Nobre, and Stokes 2011). Therefore, similar to Jongen et al. (Jongen, Smulders, and van der Heiden 2007; Jongen, Smulders, and Van Breukelen 2006), we interpret it as an early posterior component related to sensory aspects of the cue but not to attention orienting. Contrary to Vossen et al. (2016), an ADAN in response to the cue, reflecting the programming and initiation of attention shifts (Eimer 2014), was not observed. The ADAN has been considered a modality-unspecific attentional control mechanism that is mainly related to attention orienting. Recent studies however questioned this assumption, or ascribed more functionality to the occurrence of an ADAN (Talsma, Sikkens, and Theeuwes 2011). The absence of an ADAN in the current study is consistent with the notion that ADAN reflects another process than attention orienting (Green, Conder, and Mc Donald 2008; van der Lubbe et al. 2006; Praamstra, Boutsen, and Humphreys 2005). Research by van der Lubbe et al. (2006) indicated that the presence of ADAN reflects saccadic inhibition as participants need to inhibit eye movements towards target appearance. Or, as van der Lubbe et al. (2006) state: 'Ah, the right side is relevant'(EDAN); '.. I shouldn't look at the right ...'(ADAN); 'but focus my attention over there' (LDAP). Although 
Table 2. Pearson correlations.

\begin{tabular}{lcccc}
\hline & SDLP_low & SDLP_high & $\begin{array}{c}\text { Error rate_ } \\
\text { low }\end{array}$ & $\begin{array}{c}\text { Error rate_ } \\
\text { high }\end{array}$ \\
\hline SDLP_low & 1 & $0.93^{* *}$ & 0.18 & -0.33 \\
SDLP_high & $0.93^{* *}$ & 1 & 0.03 & -0.35 \\
Error rate_low & 0.18 & 0.03 & 1 & 0.30 \\
$\begin{array}{l}\text { Error rate_ } \\
\text { high }\end{array}$ & -0.33 & $-0.35^{*}$ & 0.30 & 1 \\
\hline
\end{tabular}

Notes: SDLP: lane-keeping in the low and high load. Error rate: error rate is the responses to the memory task in the low and high load.

${ }^{*} p \leq .05$ (one-tailed); ${ }^{* *} p \leq .01$ (one-tailed)

speculative, it is possible that the instruction to stay in the middle of the lane increased the ease to concentrate on the middle of the road, thereby automatically inhibiting the tendency to look at potentially relevant target locations.

The error rate on the memory task, and the false alarm rate on the orienting task, increased under high WM load. This resembles previous research indicating that WM load degrades attention (Lee, Lee, and Boyle 2009; Vossen et al. 2016). With respect to the orienting task, participants tended to respond more liberally. According to the Load theory from Lavie (Lavie 2010; Lavie et al. 2004), active maintenance of goal-directed behaviour (eg deciding to yield) in the presence of interference (ie distraction) depends on spare WM capacity. As indicated by the increased error rate on the memory task, the high WM load condition was more cognitively challenging, leaving fewer resources to devote to the decision to yield. Performance has two important aspects: speed and accuracy. Although they are qualitatively different, it is usually assumed that there exists a trade-off between the two, in the sense that a participant can generally choose to be faster, but at the cost of more errors. Dependent upon effects on the chosen strategy, subtle effects of experimental variables may either concern speed or accuracy, or both. In this case, no effects on speed were found. Therefore, participants did not compensate the decrement in performance that was caused by the high WM load (ie increased false alarms) by slowing the reaction time.

Translated to real driving, in case of high WM load and ensuing doubt, drivers have an increased tendency to yield, thereby increasing their safety margins (as found previously under conditions of increased WM load; Engström, Johansson, and Östlund 2005; Son, Lee, and Kim 2011) and reducing chances for crossing-path crashes. Therefore, the increased tendency to yield might be a compensatory strategy to deal with reduced resources to devote to the task. In this way, traffic safety would not be directly compromised by the increased WM load as unnecessary yielding may be less likely to result in an accident than failing to yield, thereby minimising risk. Nevertheless, traffic flow will be reduced when drivers stop at inappropriate times.
Indeed, distraction introduced by WM load negatively influenced traffic flow in a study from Stavrinos et al. (2013) (ie talking on the phone and most pronounced for distraction induced by writing text messages). Importantly, as reduced traffic flow might lead to congestion, traffic safety could be indirectly affected in case the increased proximity of following vehicles leads to 'secondary crashes' (eg multiple-vehicle crashes) (Stavrinos et al. 2013), which is supported by an increased likelihood of rear-end-crashes in teen drivers under conditions of increased WM load (Neyens and Boyle 2007).

The results showed no effects of WM load on ERP responses to the cue, which is in contrast to Vossen et al. (2016) who found WM load effects on markers of orienting that indicated decreased processing of the cue. However, these effects concerned modulations of ADAN and EDAN, components that did not appear to begin wit in the current study. Similar to Vossen et al. (2016), WM load did not affect markers of nonspatial orienting in response to the car stimuli. Finally, in contrast to Vossen et al. (2016), WM load decreased attentional resources available for processing a salient target-relevant event, as indicated by a reduced $\mathrm{P} 3$ in the high WM load condition for $\mathrm{Fz}$ and $\mathrm{Oz}$. As no WM load effects were found in response to the cue indicating the to-be-attended side (ie resembling a road sign indicating right-of-way) or in response to the appearance of the car (ie simulating an approaching car), WM load only affected later stages of decision-making (ie do I have to react or not). This phase probably required more baseline attentional resources as the decision is more relevant here (ie compared to lab task) because of the immersion in a driving context. Considering task description, as well as latency and scalp topography of the observed P3, the current results could reflect a decrease in P3b. The P3b is a late central-parietal component ( 400-700 ms) indicating categorisation, the update of WM, or monitoring of decision-making (Bruder, Kayser, and Tenke 2009; Verleger, Jaskowski, and Wascher 2005). Furthermore, P3b is elicited when being presented with stimuli of unequal probability and attention needs to be paid to the infrequent ones (Fjell and Walhovd 2003). This is in agreement with research where WM load decreased P3b in response to a sign indicating the direction of a required lane change (550 ms post-stimulus) (Lei, Welke, and Roetting 2009).

In line with previous research (Cuenen et al. 2015; Engström, Johansson, and Östlund 2005; He, McCarley, and Kramer 2014), the SDLP measurement indicated increased lane-keeping performance with increasing WM load. There are two prevailing theories to explain this effect (Lemercier et al. 2014). First, increased lane-keeping is accompanied by reduced visual scanning, indicating attention decrement (Reimer 2009), which could also support the argument made above for the missing 
ADAN. Second, it signals the prioritisation of driving over the memory task, indicating improved performance of the driving task compared to the memory task (Becic et al. 2010; Engström, Johansson, and Östlund 2005). Recent research favours the latter. First, higher WM load induced by performing a backward counting task, was found to relate to increased lane-keeping performance independent of eye movements during a simulated drive (Cooper, Medeiros-Ward, and Strayer 2013). Second, He, McCarley, and Kramer (2014) let participants perform a simulated lane-keeping task under conditions of lateral wind and WM load (low: listen and repeat back randomly ordered digits; high: listen, reorder, and repeat randomly ordered digits). They found a similar increase in lane-keeping performance with increasing WM load. An increased coupling of steering-to-lateral-winds under high WM load suggested that the increased lane-keeping indicated true improvement in lateral control. Therefore, participants in our study may have compensated for increasing WM load by prioritising lane-keeping. The correlation analyses provides preliminary support for this assumption as the reduced lane-keeping variability under high WM load showed a trend towards an association with higher error rate in the high WM load. This may suggest that the WM load manipulation depleted additional cognitive resources, in line with Lavie's theory (Lavie 2010; Lavie et al. 2004). As in He, McCarley, and Kramer (2014), it is still not clear why drivers would selectively protect lateral control as participants were not instructed to prioritise lane-keeping. Driving - at least in more experienced drivers - can be considered a highly overlearned behaviour. Therefore, it is quite plausible that the prioritisation of lane-keeping is a reflexive adaptation. It is possible that drivers did not voluntarily and consciously prioritised lane-keeping but rather performed automatically. Cooper, Medeiros-Ward, and Strayer (2013) suggested that under conditions of high WM load, lane-keeping becomes an encapsulated innerloop process requiring minimal attention, a process they describe as being similar to the swing of professional golf players which has been found to degrade when attention is paid to it (Cooper, Medeiros-Ward, and Strayer 2013). However, as we were not able to find a highly significant relation between lane-keeping variability and error rate under conditions of high WM load, further research is necessary to support our hypothesis.

\section{Limitations}

First, questions can be raised concerning the ecological validity of these results as the driving context was rather simplistic, while driving through intersections in real-life can be extremely complicated. The simplified nature of the driving task allowed us to investigate ERPs related to attention orienting, which would otherwise be compromised by movement. The choice of a simplistic scenario can be further justified by a driving simulator study (Werneke and Vollrath 2012) that found the highest level of crashes at the least complicated intersections and attributed this result to inadequate attention allocation. However, future studies should evaluate the effect of intersection complexity as it is likely that drivers will show stronger attentional effects as in the current study and possibly then also stronger modulation by load. Second, to minimise experimental duration (the current procedure took three to four hours) and reduce fatigue effects, we decided against a control condition without any load of WM. As the low WM load condition was already quite demanding due to the combination with the orienting task and active lane-keeping, a contrast with a truly non-demanding baseline condition (no memory task) might have revealed additional effects of WM load. Nevertheless, this situation more closely resembles true driving which is executed in a dynamic and complex environment requiring vehicle control in changing circumstances. Third, as a crash would discontinue cruise control, vehicles owning right-of-way did not complete their manoeuver to drive onto the road. A study from China indicated that drivers decide to yield $1.3-1.5 \mathrm{~s}$ before reaching the merging point at unsignalised intersections (ie no priority control) (Liu et al. 2013), leaving a time-window between the decision and the event. From the current results, it is not possible to determine how drivers might have reacted during this limited time-gap from brake-onset to the merging point. Transferred to the current study, it is possible that drivers might brake initially but then continue driving when they realise their mistake (ie false alarm). If the other driver, not owning right-of-way, notices the brake reaction and assumes that the other driver will stop, the risk of a crossing-path crash increases when decides to cross as well.

\section{Recommendations}

Intersection driver-support systems have been used to improve traffic safety, and recently also traffic flow (eg Chen, Cao, and Logan 2011; Dotzauer et al. 2015). Still, in-vehicle systems induce WM load, even without using visual stimuli (Becic et al. 2012, 2013; Solovey et al. 2014). As this could increase the tendency to yield, thereby affecting traffic flow, the effectiveness of such systems might be reduced. Therefore, WM load measurements should be included when developing intersection driver-support systems. One option to assess the WM load of drivers is to include EEG measurement to intersection driver-support systems (Lei, Welke, and Roetting 2009). Previous research already investigated the use of ERPs to measure WM load with the use of a secondary task (Coleman et al. 
2015; Lei, Welke, and Roetting 2009). For instance, Coleman et al. (2015) found an increased P3 latency, in conjunction with a reduced amplitude, in a signal detection task when drivers interact with in-vehicle voice-command systems resembling varying levels of WM load. The use of ERPs in response to the driving task to measure WM load is further supported by previous research indicating a reduction of P3 amplitude in response to brake lights of a leading vehicle in a car-following-task, while drivers were talking on the phone (Strayer and Drews 2007). A major concern however is the practical applicability of EEG during active driving. For instance, in the study by Coleman et al. (2015), there was a degradation of signal quality due to increased environmental noise (eg computers), making the transfer to on-road driving, where even more noise will be present, challenging.

\section{Conclusions}

The current results provide support for the theory from Lavie that performance depends on available WM resources (Lavie 2010; Ross et al. 2014). Although lane-keeping increased under high WM load, task performance decreased as indicated by an increased error rate in the memory task, increased tendency to inappropriately yield in the orienting task, and a smaller P3 in response to movement. Furthermore, this study confirmed that typical markers of attention orienting can be found in more ecologically valid settings. However, discrepancies between the current study and Vossen et al. (2016) need further investigation. Although further applications in even more realistic driving environments are called for, the current results support the usefulness of WM load measurement during driving in the development of driver-support systems.

\section{Disclosure statement}

No potential conflict of interest was reported by the authors.

\section{ORCID}

Geert Wets (D) http://orcid.org/0000-0002-5485-9705

\section{References}

Allen, R. W., T. D. Marcotte, T. J. Rosenthal, and B. L. Aponso 2005. "Driver Assessment with Measures of Continuous Control Behavior." In Proceedings of the Third International Driving Symposium on Human Factors in Driver Assessment, Training and Vehicle Design, 165-172. San Diego, CA: University of lowa.

Bao, S., and L. N. Boyle. 2009. “Age-related Differences in Visual Scanning at Median-divided Highway Intersections in Rural Areas." Accident Analysis and Prevention 41: 146-152.
Becic, E., G. S. Dell, K. Bock, S. M. Garnsey, T. Kubose, and A. F. Kramer. 2010. "Driving Impairs Talking." Psychonomic Bulletin \& Review 17 (1): 15-21. doi:10.3758/PBR.17.1.15.

Becic, E., M. P. Manser, J. I. Creaser, and M. Donath. 2012. "Intersection Crossing Assist System: Transition from a Roadside to an in-vehicle System." Transportation Research Part F: Traffic Psychology and Behaviour 15: 544-555. doi:10.1016/j. trf.2012.05.010

Becic, E., M. Manser, C. Drucker, and M. Donath. 2013. "Aging and the Impact of Distraction on an Intersection Crossing Assist System." Accident Analysis and Prevention 50: 968-974. doi:10.1016/j.aap.2012.07.025.

Bruder, G. E., J. Kayser, and C. E. Tenke. 2009. "Event-related Brain Potentials in Depression: Clinical, Cognitive and Neurophysiologic Implications." In The Oxford Handbook of Event-related Potential Components, edited by S. J. Kappenman, and S. J. Luck, 563-592. New York: Oxford University Press.

Chen, H., L. Cao, and D. B. Logan. 2011. "Investigation into the Effect of an Intersection Crash Warning System on Driving Performance in a Simulator." Traffic Injury Prevention 12: 529537.

Coleman, J. R., J. Turrill, R. J. Hopman, J. M. Cooper, and D. L. Strayer. 2015. "Assessing Cognitive Distraction Using Event Related Potentials." In Proceedings of the Eighth International Driving Symposium on Human Factors in Driver Assessment Training and Vehicle Design. Salt Lake City, UT.

Cooper, J. M., N. Medeiros-Ward, and D. L. Strayer. 2013. "The Impact of Eye Movements and Cognitive Workload on Lateral Position Variability in Driving." Human Factors: The Journal of the Human Factors and Ergonomics Society 55 (5): 1001-1014. doi: $10.1177 / 0018720813480177$

Cuenen, A., E. M. Jongen, T. Brijs, K. Brijs, M. Lutin, K. Van Vlierden, and G. Wets. 2015. "Does Attention Capacity Moderate the Effect of Driver Distraction in Older Drivers?" Accident Analysis and Prevention 77: 12-20.

De Waard, D. (1996). The Measurement of Drivers' Mental Workload. Unpublished doctoral diss., Haren: University of Groningen; The Netherlands: University of Groningen Traffic Research Centre.

Dotzauer, M., D. de Waard, S. R. Caljouw, G. Pöhler, and W. H. Brouwer. 2015. "Behavioral Adaptation of Young and Older Drivers to an Intersection Crossing Advisory System." Accident Analysis and Prevention 74: 24-32. doi:10.1016/j. aap.2014.09.030

Eimer, M. 2014. "The Time Course of Spatial Attention: Insights from Event-related Brain Potentials." In The Oxford Handbook of Attention, edited by A. Nobre, and S. Kastner, 289-317. Oxford: Oxford University Press.

Engström, J., E. Johansson, and J. Östlund. 2005. "Effects of Visual and Cognitive Load in Real and Simulated Motorway Driving." Transportation Research Part F: Traffic Psychology and Behaviour 8 (2): 97-120.

Fjell, A. M., and K. B. Walhovd. 2003. "On the Topography of P3a and P3b across the Adult Lifespan-A Factor-analytic Study Using Orthogonal Procrustes Rotation." Brain Topography 15 (3): 153-164.

de Fockert, J. W., G. Rees, C. D. Frith, and N. Lavie. 2001. “The Role of Working Memory in Visual Selective Attention." Science 291: 1803-1806.

Fort, A., B. Collette, M. Bueno, P.Deleurence, and A. Bonnard. 2013. "Impact of Totally and Partially Predictive Alert in Distracted and Undistracted Subjects: An Event Related Potential Study." 
Accident Analysis and Prevention 50: 578-586. doi:10.1016/j. aap.2012.06.005. doi:10.1016/j.brainres.2010.09.094.

Fu, C., Y. Pei, Y.Wu, and W. Qi. 2013. "The Influence of Contributory Factors on Driving Violations at Intersections: An Exploratory Analysis." Advances in Mechanical Engineering 2013: 8. doi:10.1155/2013/905075.

Green, J. J., J. A. Conder, and J. J. Mc Donald. 2008. “Lateralized Frontal Activity Elicited by Attention-directing Visual and Auditory Cues." Psychophysiology 45: 579-587. doi:10.1111/ j.1469-8986.2008.00657.x.

He, J., J. S. McCarley, and A. F. Kramer. 2014. "Lane Keeping under Cognitive Load." Human Factors: The Journal of the Human Factors and Ergonomics Society 56 (2): 414-426. doi:10.1177/0018720813485978.

Herrmann, C. S., and R. T. Knight. 2001. "Mechanisms of Human Attention: Event-related Potentials and Oscillations." Neuroscience \& Biobehavioral Reviews 25 (6): 465-476.

Horberry, T., J. Anderson, M. A. Regan, T. J. Triggs, and J. Brown. 2006. "Driver Distraction: The Effects of Concurrent in-vehicle Tasks, Road Environment Complexity and Age on Driving Performance." Accident Analysis \& Prevention 38 (1): 185-191.

Jongen, E. M., F. T. Smulders, and J. S. van der Heiden. 2007. "Lateralized ERP Components Related to Spatial Orienting: Discriminating the Direction of Attention from Processing Sensory Aspects of the Cue." Psychophysiology 44: 968-986.

Jongen, E. M., F. T. Smulders, and G. J. Van Breukelen. 2006. "Varieties of Attention in Neutral Trials: Linking RT to ERPs and EEG Frequencies." Psychophysiology 43: 113-125.

van Kessel, M. E., A. C. Geurts, W. H. Brouwer, and L. Fasotti. 2013. "Visual Scanning Training for Neglect after Stroke with and without a Computerized Lane Tracking Dual Task." Frontiers in Human Neuroscience 7 (358): 1.

Kessels, L. T., R. A. Ruiter, and B. M. Jansma. 2010. "Increased Attention but More Efficient Disengagement: Neuroscientific Evidence for Defensive Processing of Threatening Health Information." Health Psychology 29 (4): 346-354.

Lavie, N. 2010. "Attention, Distraction, and Cognitive Control under Load." Current Directions in Psychological Science 19 (3): 143-148.

Lavie, N., A. Hirst, J. W. de Fockert, and E. Viding. 2004. "Load Theory of Selective Attention and Cognitive Control." Journal of Experimental Psychology: General 133 (3): 339-354.

Law, A. S., S. R. Langton, and R. H. Logie. 2010. "Assessing the Impact of Verbal and Visuospatial Working Memory Load on Eye-gaze Cueing." Visual Cognition 18 (10): 1420-1438.

Lee, Y.-C., J. D. Lee, and L. N. Boyle. 2009. "The Interaction of Cognitive Load and Attention-directing Cues in Driving." Human Factors: The Journal of the Human Factors and Ergonomics Society 51 (3): 271-280. doi:10.1177/0018720809337814.

Lei, S., S. Welke, and M. Roetting. 2009. “Driver's Mental Workload Assessment Using EEG Data in a Dual Task Paradigm." In Proceedings of the 21st (ESV) International Technical Conference on the Enhanced Safety of Vehicles. Berlin.

Lemercier, C., C. Pêcher, G. Berthié, B. Valéry, V. Vidal, P.-V. Paubel, M. Cour, A. Fort, C. Galéra, E. Lagarde, and B. Maury. 2014. "Inattention behind the Wheel: How Factual Internal Thoughts Impact Attentional Control While Driving." Safety Science 62: 279-285.

Liu, M., G. Lu, Y. Wang, Y. Wang, and Z. Zhang. 2013. “Preempt or Yield? An Analysis of Driver's Dynamic Decision Making at Unsignalized Intersections by Classification Tree." Safety Science 65: 36-44. doi:10.1016/j.ssci.2013.12.009 van der Lubbe, R. H., S. F. Neggers, R. Verleger, and L. J. Kenemans. 2006. "Spatiotemporal Overlap between Brain Activation Related to Saccade Preparation and Attentional Orienting." Brain Research 1072: 133-152. doi:10.1016/j. brainres.2005.11.087.

Luck, S. J., H. J. Heinze, G. R. Mangun, and S. A. Hillyard. 1990. "Visual Event-related Potentials Index Focused Attention within Bilateral Stimulus Arrays. II. Functional Dissociation of P1 and N1 Components." Electroencephalography and Clinical Neurophysiology 75 (6): 528-542.

McDonald, J. J., and J. J. Green. 2008. "Isolating Event-related Potential Components Associated with Voluntary Control of Visuo-spatial Attention." Brain Research 1227: 96-109. doi:10.1016/j.brainres.2008.06.034.

McEvoy, S. P., M. R. Stevenson, and M. Woodward. 2007. "The Prevalence of, and Factors Associated with, Serious Crashes Involving a Distracting Activity." Accident Analysis and Prevention 39: 475-482. doi:10.1016/j.aap.2006.09.005.

McGinnis, M. E., and A. Keil. 2011. "Selective Processing of Multiple Features in the Human Brain: Effects of Feature Type and Salience." PLOS ONE 6 (2): 12. doi:10.1371/journal. pone.0016824.

Murray, A. M., A. C. Nobre, and M. G. Stokes. 2011. "Markers of Preparatory Attention Predict Visual Short-term Memory Performance."Neuropsychologia 49: 1458-1465. doi:10.1016/j. neuropsychologia.2011.02.016.

Neyens, D. M., and N. L. Boyle. 2007. "The Effect of Distractions on the Crash Types of Teenage Drivers." Accident Analysis and Prevention 39: 206-212. doi:10.1016/j.aap.2006.07.004.

Nobre, A. C., G. N. Sebestyen, and C. Miniussi. 2000. "The Dynamics of Shifting Visuospatial Attention Revealed by Event-related Potentials." Neuropsychologia 38: 964 \pm 974.

Pitts, M. A., J. Padwal, D. Fennelly, A. Martínez, and S. A. Hillyard. 2014. "Gamma Band Activity and the P3 Reflect Postperceptual Processes, Not Visual Awareness." Neurolmage 101: 337-350. doi:10.1016/j.neuroimage.2014.07.024.

Posner, M. I. 1978. "Attended and Unattended Processing Modes: The Role of Set for Spatial Location." In Modes of Perceiving and Processing Information. Vol. 137, edited by H. L. Pick and E. Saltzman, 137-157. New York: Taylor \& Francis Group.

Praamstra, P., L. Boutsen, and G. W. Humphreys. 2005. Frontoparietal Control of Spatial Attention and Motor Intention in Human EEG. Journal of Neurophysiology 94: 764774. doi:10.1152/jn.01052.2004.

Prinzel, L. J., F. G. Freeman, M. W. Scerbo, P. J. Mikulka, and A.T. Pope. 2003. "Effects of a Psychophysiological System for Adaptive Automation on Performance, Workload, and the Event-related Potential P300 Component." Human Factors: The Journal of the Human Factors and Ergonomics Society 45 (4): 601-613.

Ramaekers, J. G. 2003. "Antidepressants and Driver Impairment." The Journal of Clinical Psychiatry 64 (1): 20-29.

Recarte, M. A., and L. M. Nunes. 2003. "Mental Workload While Driving: Effects on Visual Search, Discrimination, and Decision Making." Journal of Experimental Psychology: Applied 9 (2): 119-137.

Reimer, B. 2009. "Impact of Cognitive Task Complexity on Drivers' Visual Tunneling." Transportation Research Record: Journal of the Transportation Research Board 2138: 13-19. doi:10.3141/2138-03.

Ross, V., E. M. Jongen, T. Brijs, K. Brijs, R. A. Ruiter, and G. Wets. 2015. "The Relation between Cognitive Control and Risky Driving in Young Novice Drivers." Applied Neuropsychology: Adult 22 (1): 61-72. doi:10.1080/23279095.2013.838958. 
Ross, V., E. M. Jongen, W. Wang, T. Brijs, K. Brijs, R. A. Ruiter, and G. Wets. 2014. "Investigating the Influence of Working Memory Capacity When Driving Behavior is Combined with Cognitive Load: An LCT Study of Young Novice Drivers." Accident Analysis and Prevention 62: 377-387.

Ruiter, R. A., L. T. Kessels, B. M. Jansma, and J. Brug. 2006. "Increased Attention for Computer-tailored Health Communications: An Event-related Potential Study." Health Psychology 25 (3): 300-306.

Sandin, J. 2009. "An Analysis of Common Patterns in Aggregated Causation Charts from Intersection Crashes." Accident Analysis and Prevention 41: 624-632.

Santangelo, V., P. Finoia, A. Raffone, M. O. Belardinelli, and C. Spence. 2008. "Perceptual Load Affects Exogenous Spatial Orienting While Working Memory Load Does Not." Experimental Brain Research 184: 371-382.

Shedden, J. M., and C. L. Nordgaard. 2001. "ERP Time Course of Perceptual and Post-perceptual Mechanisms of Spatial Selection." Cognitive Brain Research 11: 59-75.

Solovey, E. T., M. Zec, E. A. Perez, B. Reimer, and B. Mehler. 2014. "Classifying Driver Workload Using Physiological and Driving Performance Data: Two Field Studies." In ACM CHI Conference on Human Factors in Computing Systems. Toronto, Canada.

Son, J., Y. Lee, and M. H. Kim. 2011. "Impact of Traffic Environment and Cognitive Workload on Older Drivers' Behavior in Simulated Driving." International Journal of Precision Engineering and Manufacturing 12 (1): 135-141.

Stavrinos, D., J. L. Jones, A. A. Garner, R. Griffin, C. A. Franklin, D. Ball, S. C. Welburn, K. K. Ball, V. P. Sisiopiku, and P. R. Fine. 2013. "Impact of Distracted Driving on Safety and Traffic Flow." Accident Analysis and Prevention 61: 63-70. doi:10.1016/j. aap.2013.02.003.

Strayer, D. L., and F. A. Drews. 2007. "Cell-phone-Induced Driver Distraction." Current Directions in Psychological Science 16 (3): 128-131.

Strayer, D. L., F. A. Drews, and W. A. Johnston. 2003. "Cell Phoneinduced Failures of Visual Attention during Simulated Driving." Journal of Experimental Psychology: Applied 9 (1): 23-32.
Talsma, D., J. J. Sikkens, and J. Theeuwes. 2011. "Stay Tuned: What is Special about Not Shifting Attention?" PLOS ONE 6 (3): e16829. doi:10.1371/journal.pone.0016829.

Ullsperger, P., G. Freude, and U. Erdmann. 2000. "Auditory Probe Sensitivity to Mental Workload Changes - An Event-related Potential Study." International Journal of Psychophysiology 40: 201-209.

Van Velzen, J., and M. Eimer. 2003. "Early Posterior ERP Components Do Not Reflect the Control of Attentional Shifts toward Expected Peripheral Events." Psychophysiology 40: 827-831.

Verleger, R., P. Jaskowski, and E. Wascher. 2005. “Evidence for an Integrative Role of P3b in Linking Reaction to Perception." Journal of Psychophysiology 19 (3): 165-181.

Vossen, A. Y., V. Ross, E. M. Jongen, R. A. Ruiter, and F. T. Smulders. 2016."Effect ofWorking Memory Load on Electrophysiological Markers of Visuospatial Orienting in a Spatial Cueing Task Simulating a Traffic Situation." Psychophysiology 53 (2): 237251. doi:10.1111/psyp.12572.

Werneke, J., and M. Vollrath. 2012. "What Does the Driver Look at? The Influence of Intersection Characteristics on Attention Allocation and Driving Behavior." Accident Analysis and Prevention 45: 610-619.

Wester, A. E., K. B. Bocker, E. R. Volkerts, J. C. Verster, and J. L. Kenemans. 2008. "Event-related Potentials and Secondary Task Performance during Simulated Driving." Accident Analysis and Prevention 40: 1-7.

World Health Organization. 2013. Global Status Report on Road Safety 2013: Supporting a Decade of Action. August, 2014. https://www.who.int/violence_injury_prevention/road_ safety_status/2013/en/.

Wu, N. 2001. "A Universal Procedure for Capacity Determination at Unsignalized (Priority-controlled) Intersections." Transportation Research Part B: Methodological 35 (6): 593-623. doi:10.1016/ S0191-2615(00)00012-6.

Young, K., and M. Regan. 2007. "Driver Distraction: A Review of the Literature." In Distracted Driving, edited by I. J. Faulks, M. Regan, M. Stevenson, J. Brown, A. Porter, and J. D. Irwin, 379-405). Sydney: NSW: Australasian College of Road Safety. 